\title{
ANTIBACTERIAL AND ANTI-OXIDANT ACTIVITIES OF LAUREL OIL AGAINST Staphylococcus aureus AND Pseudomonas fluorescence IN Oreochromis niloticus FILLETS
}

\author{
Ebeed A. Saleh ${ }^{1 *}$, Ibrahim I. Al-Hawary², Mayada M.Elnajar ${ }^{3}$
}

${ }^{1}$ Department of Food Hygiene, Faculty of Veterinary Medicine, Damanhour University, Egypt, ${ }^{2}$ Department of Fish Processing and Biotechnology, Faculty of Aquatic and Fisheries Science, Kafrelsheikh University, Egypt, ${ }^{3}$ Department of Food Hygiene, Faculty of Veterinary Medicine, Damanhour University

${ }^{*}$ Corresponding author, E-mail: ebeed.saleh@yahoo.com

\begin{abstract}
Laurus nobilis L. commonly known as Bay belonging to the family Lauraceae, is one of the most useful plant used in foods as a spice in Mediterranean cookery. This study was designed to evaluate the antibacterial and anti-oxidant activities of different concentrations of laurel essential oil $(0.5 \%, 1 \%, 1.5 \%)$ against two bacterial strains "Staphylococcus aureus as food poisoning bacteria and Pseudomonas fluorescence as food spoilage bacteria" in order to enhance fish safety and increase shelf life. A total of 80 samples of freshly dead Oreochromis niloticus fish were collected after experimental infection with the two bacterial strains followed by treatment with different concentrations of laurel essential at different storage time at chilling temperature. The results showed that laurel essential oil was efficient against the tested bacteria, but varied in its antibacterial activity as follows; the highest reduction percent of $S$. aureus and $P$. fluorescence at rate of $99.97 \%$ and $94.5 \%$ was detected 6 days after laurel oil treatment, respectively, and reached $100 \% 9$ day after oil treatment at the same concentration. While the lowest value was obtained with $0.5 \%$ concentration. Laurel oil (1.5\%) also showed a significant decrease in $\mathrm{pH}, \mathrm{TNB}-\mathrm{N}$ and TBA. Based on the obtained data, it could be concluded that, laurel essential oil has strong antibacterial and antioxidant activity against the tested bacteria, so that it can be used as natural food preservatives alternatives to other synthetic agents to keep quality and increase fish shelf life.
\end{abstract}

Key words: Laurus nobilis; essential oil; antibacterial activity; fish shelf-life; food safety

\section{Introduction}

Fish is an important source of protein to humans which rich of many sources of therapeutically important polyunsaturated fatty acids, vitamins and various other micro nutrients. Seafood has a limited shelf life due to it is highly perishable, microbial spoilage is the main cause of fish decomposition (1). It affects both the quality and the safety of fish and leads to food poisoning, so that the concepts of enhancing its shelf life and quality became needful in the recent years (2).

Due to the highly potential health hazard of synthetic preservatives and its toxicological effects, natural preservatives have been explored 
by the researchers for controlling the microbial and chemical mechanisms responsible for spoilage in fish (3).

Plant extracts are safe, effective and successful treatments with the potential to extend the shelf life of foods. Plant extracts and its essential oils have antimicrobial and anti-oxidant properties against food borne pathogens, today they have been considered as natural preservatives or food additives in food industry for raw and processed food preservation (4). Bay laurel (Laurus nobilis L.) is an evergreen shrub native to the Mediterranean region, being the only European representative of the Lauraceae family. Its dried leaves and essential oil are used in Italy France, Turkey, Algeria, Morocco, Spain, Portugal and Mexico as a valuable spice in the culinary and food industry (5).

Thus, the aim of this study was to evaluate the antibacterial and antioxidant activities of laurel essential oil against two bacterial strains "Staphylococcus aureus as food poisoning and Pseudomonas fluorescence as food spoilage bacteria " for enhancing shelf life of fish.

\section{Materials and methods}

\section{Collection and preparation of samples}

A total of 80 samples of freshly dead Orechromis niloticus fishes were collected from local market at Kafrelsheikh Governorates and transferred quickly to the Lab of "Animal Health Research Institute" for bacteriological and chemical examination. Then fishes were swabbed with ethyl alcohol $70 \%$ and scorched with flame, the fish flesh taken from the back muscle (6). Fillets cut with a sterile scalpel to $(100 \mathrm{~g})$, put under the UV light for 20 minutes to reduce number of the microorganisms attached to its surface.

\section{Preparations of inocula}

Staphylococcus aureus and Pseudomonas fluorescence strains were obtained from Food Analysis Center, Faculty of Veterinary Medicine, Benha University, Egypt. Bacteria were sub-cultured on Brain-Heart Infusion (BHI) broth and harvested by centrifugation $(3000 \times \mathrm{g}$, $15 \mathrm{~min})$, and resuspended with saline $(\mathrm{NaCl}$,
$0.85 \%$, w.v) (7). For inoculation of the Oreochromis niloticus fillets, $1 \mathrm{ml}$ of the dense suspension $3 \times 10^{6} / \mathrm{g}$ for each strains was employed.

\section{Essential oil extraction}

Extraction of the plant material was applied by immersion in absolute methanol for three days using automatic shaker. Then twice filtrations were applied to remove solid and fine plant particles. The enriched extract was concentrated by evaporation with heating in water bath at $65^{\circ} \mathrm{C}$ until solid mass was obtained. Finally, spreading under shaded area till complete dryness and stored in the refrigerator until using. Each extract was used for preparation of $1 \%(\mathrm{w} / \mathrm{v})$ solution $(8)$, then was inoculated into Oreochromis niloticus fillets.

\section{Bacteriological examination}

To $25 \mathrm{~g}$ of the sample, $225 \mathrm{ml}$ of sterile peptone water were added and mixed, for preparation tenfold serial dilutions for the further examinations (9). A volume of $0.1 \mathrm{ml}$ of this serial dilution was spread over Baired Parker agar plate, then the plate was incubated at $37^{\circ} \mathrm{C}$ for 48 h. S.aureus count /g was calculated (10). A volume of $0.1 \mathrm{ml}$ of each sample homogenate was separately inoculated into duplicate petridishes of Pseudomonas selective agar medium and was evenly spread, then the developed colonies (greenish yellow colonies) were counted (11).

\section{Chemical examination}

Ten grams of sample were blended in $10 \mathrm{ml}$ of neutralized distilled water. The $\mathrm{pH}$ value was determined by using an electrical $\mathrm{pH}$ meter (Bye model 6020, USA) (12). The technique applied for determination of total volatile nitrogen (TVN) was recommended by Food and Agriculture Organization "FAO" (1980) (13) . Determination of thiobarbituric acid number (TBA) (mg malonaldehyde/kg) was recommended by Pikul et al. (1989) (14). 
Statistical Analysis

The obtained results were statistically evaluated by application of Analysis of Variance (ANOVA) test according to Feldman et al. (15).

\section{Results}

\section{Antibacterial activity}

S. aureus inoculated fillets showed a significant reduction following addition of different Laurel oil concentration at different storage time. The highest reduction percent was at $1.5 \%$ concentration of oil by $98.63 \%, 99.97 \%$ and $100 \%$ after 3, 6 and 9 day of treatment, while the lowest reduction showed at $0.5 \%$ concentration by $40 \%, 75.26 \%$ and $86.9 \%$ after 3,6 and 9 day of treatment (Table 1).

In the case of P.fluorescence inoculated fillets, it displayed a lower reduction percent compared to S.aureus inoculated fillets also, it showed significant reduction percent with different concentration, at $0.5 \%$ concentration the reduction was $21.33 \%, 62 \%$ and $69.13 \%$ after the 3,6 and 9 day of treatment, at $1 \%$ concentration the reduction was $48.67 \%, 70.12 \%$ and $93.89 \%$ after 3,6 , and 9 day of treatment, the higher reduction percent was at $1.5 \%$ concentration by $82.43 \%, 94.15 \%, 100 \%$ after 3,6 and 9 day of treatment with laurel oil (Table 2).

Table 1: Antibacterial activity of essential oil of laurel on S.aureus inoculated into Oreochromis niloticus fillets by intensity of $3 \times 10^{6} / \mathrm{g}(\mathrm{n}=5)$

\begin{tabular}{|c|c|c|c|c|c|c|c|c|}
\hline \multirow{2}{*}{$\begin{array}{l}\text { Treatment } \\
\text { Storage } \\
\text { time }\end{array}$} & \multicolumn{2}{|c|}{ Control } & \multicolumn{2}{|l|}{$\begin{array}{c}0.5 \% \\
\text { Laurel oil }\end{array}$} & \multicolumn{2}{|c|}{$\begin{array}{c}1 \% \\
\text { Laurel oil }\end{array}$} & \multicolumn{2}{|c|}{$\begin{array}{c}1.5 \% \\
\text { Laurel oil }\end{array}$} \\
\hline & Count & $\underset{\% *}{\mathbf{R}}$ & Count & R \% & Count & R \% & Count & R \% \\
\hline Zero time & $\begin{array}{c}3.0 \times 10^{6} \pm \\
0.2 \times 10^{6}\end{array}$ & ------ & & ------ & $\begin{array}{c}3.0 \times 10^{6} \pm \\
0.2 \times 10^{6}\end{array}$ & ------ & $3.0 \times 10^{6} \pm$ & ------ \\
\hline 3 days & $\begin{array}{c}2.89 \times 10^{6} \pm \\
0.1 \times 10^{6}\end{array}$ & 3.67 & $\begin{array}{c}3.0 \times 10^{6} \pm 0.2 \times 10^{6} \\
1.80 \times 10^{6} \pm 0.2 \times 10^{6}\end{array}$ & 40 & $\begin{array}{c}9.64 \times 10^{5} \pm \\
2.0 \times 10^{5}\end{array}$ & 67.86 & $\begin{array}{c}0.2 \times 10^{6} \\
4.11 \times 10^{4} \pm \\
0.7 \times 10^{4}\end{array}$ & 98.63 \\
\hline 6 days & $\begin{array}{c}2.66 \times 10^{6} \pm \\
0.3 \times 10^{6}\end{array}$ & 11.33 & $\begin{array}{l}7.42 \times 10^{5} \pm 1.5 \times 10^{5} \\
3.93 \times 10^{5} \pm 1.1 \times 10^{5}\end{array}$ & 75.26 & $\begin{array}{c}5.37 \times 10^{4} \pm \\
0.8 \times 10^{4}\end{array}$ & 98.22 & $\begin{array}{l}0.7 \times 10^{4} \\
9.0 \times 10^{2} \pm \\
16 \times 10^{2}\end{array}$ & 99.97 \\
\hline 9 days & $\begin{array}{c}2.59 \times 10^{6} \pm \\
0.2 \times 10^{6}\end{array}$ & 13.67 & & 86.90 & $\begin{array}{c}2.50 \times 10^{3} \pm \\
0.4 \times 10^{3}\end{array}$ & 99.91 & $\begin{array}{c}1.6 \times 10^{2} \\
\mathrm{ND}\end{array}$ & ------ \\
\hline
\end{tabular}

$\mathrm{R} \% *=$ Reduction \%; ND= Not detected; Reduction \%= count before - count after / count before $\mathrm{x} 100$

Table 2: Antibacterial activity of essential oil of laurel on $P$. fluorescence inoculated into Oreochromis niloticus fillets by intensity of $3 \times 10^{6} / \mathrm{g}(\mathrm{n}=5)$

\begin{tabular}{|c|c|c|c|c|c|c|c|c|}
\hline Treatment & Control & & $\begin{array}{l}0.5 \% \\
\text { Laurel oil }\end{array}$ & & $\begin{array}{l}1 \% \\
\text { Laurel oil }\end{array}$ & & $\begin{array}{l}1.5 \% \\
\text { Laurel oil }\end{array}$ & \\
\hline Storage time & Count & $\mathbf{R} \% *$ & Count & R \% & Count & R \% & Count & R \% \\
\hline Zero time & $\begin{array}{l}3.0 \times 10^{6} \pm \\
0.2 \times 10^{6}\end{array}$ & ------ & $\begin{array}{l}3.0 \times 10^{6} \pm \\
0.2 \times 10^{6}\end{array}$ & ------ & $\begin{array}{l}3.0 \times 10^{6} \pm \\
0.2 \times 10^{6}\end{array}$ & ------ & \multirow{4}{*}{$\begin{array}{l}3.0 \times 10^{6} \pm \\
0.2 \times 10^{6} \\
5.27 \times 10^{5} \pm \\
1.03 \times 10^{5} \\
1.65 \times 10^{4} \pm \\
0.21 \times 10^{4} \\
\text { ND }\end{array}$} & ------ \\
\hline 3 days & $\begin{array}{l}2.95 \times 10^{6} \pm \\
0.24 \times 10^{6}\end{array}$ & 1.67 & $\begin{array}{l}2.36 \times 10^{6} \pm \\
0.19 \times 10^{6}\end{array}$ & 21.33 & $\begin{array}{l}1.54 \times 10^{6} \pm \\
0.12 \times 10^{6}\end{array}$ & 48.67 & & 82.43 \\
\hline 6 days & $\begin{array}{l}2.87 \times 10^{6} \pm \\
0.17 \times 10^{6}\end{array}$ & 4.33 & $\begin{array}{l}1.14 \times 10^{6} \pm \\
0.08 \times 10^{6}\end{array}$ & 62 & $\begin{array}{l}8.97 \times 10^{5} \pm \\
1.65 \times 10^{5}\end{array}$ & 70.12 & & 94.50 \\
\hline 9 days & $\begin{array}{l}2.84 \times 10^{6} \pm \\
0.22 \times 10^{6}\end{array}$ & 5.33 & $\begin{array}{l}9.26 \times 10^{5} \pm \\
1.84 \times 10^{5}\end{array}$ & 69.13 & $\begin{array}{l}1.81 \times 10^{5} \pm \\
0.25 \times 10^{5}\end{array}$ & 93.89 & & ----- \\
\hline
\end{tabular}

$\mathrm{R} \% *=$ Reduction $\% ; \mathrm{ND}=$ Not detected

Different concentration of laurel oil showing significant reduction percent of S.aureus and P.fluorescence at different storage time; the highest reduction $\%$ was $1.5 \%$ laurel oil by $100 \%$ reduction after the 9 day of treatment. 

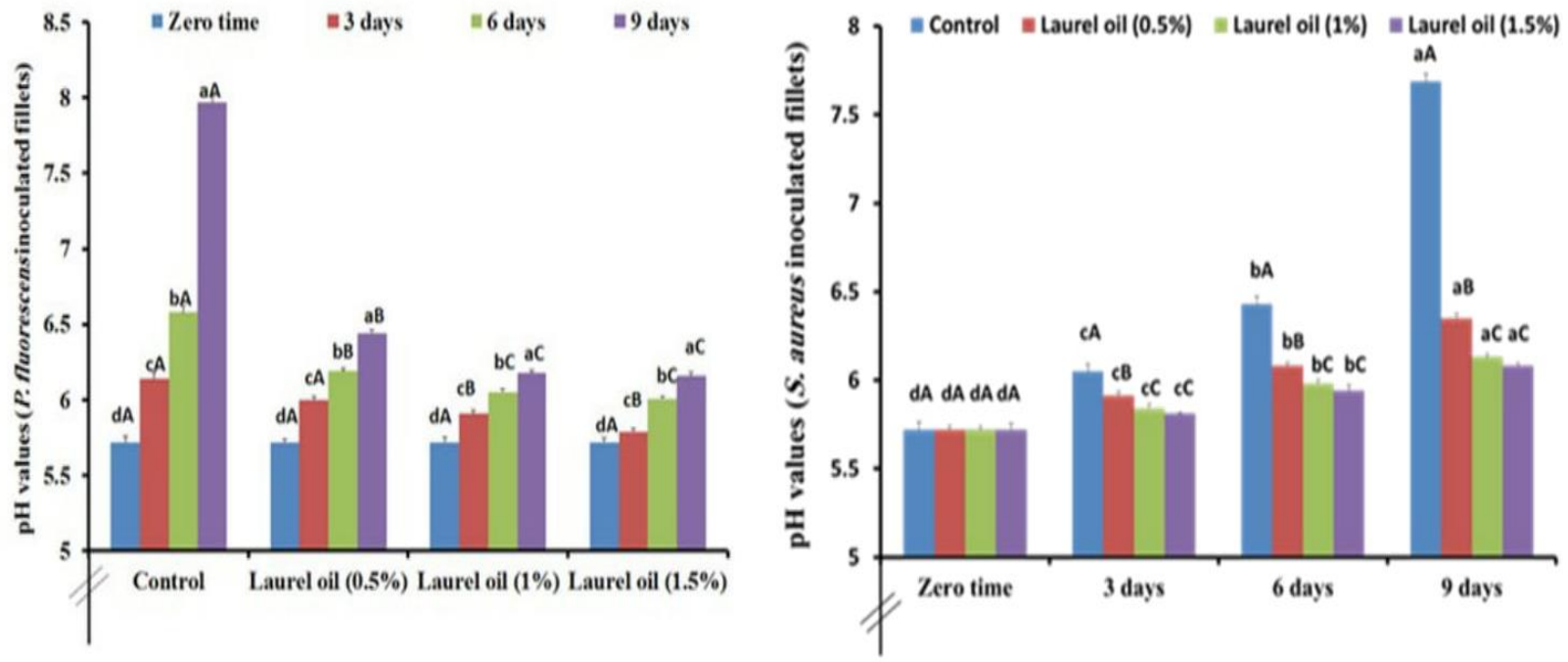

Figure 1: Showing $\mathrm{pH}$ values of S.aureus and P.fluorescence inoculated Oreochromis niloticus fillets for control and Laurel oil $(0.5 \%, 1 \%, 1.5 \%)$ concentration at different storage time
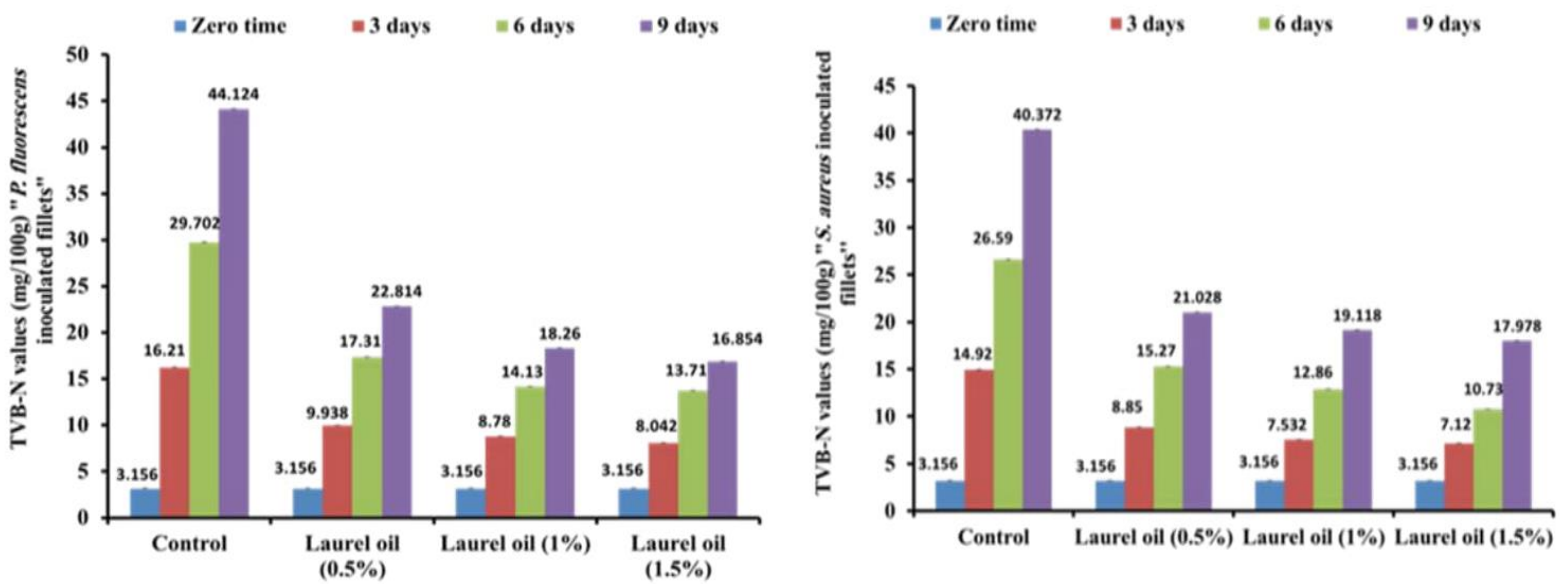

Figure 2: Showing TVB-N values of S.aureus and P.fluorescence inoculated Oreochromis niloticus fillets for control and Laurel oil $(0.5 \%, 1 \%, 1.5 \%)$ concentration at different storage time
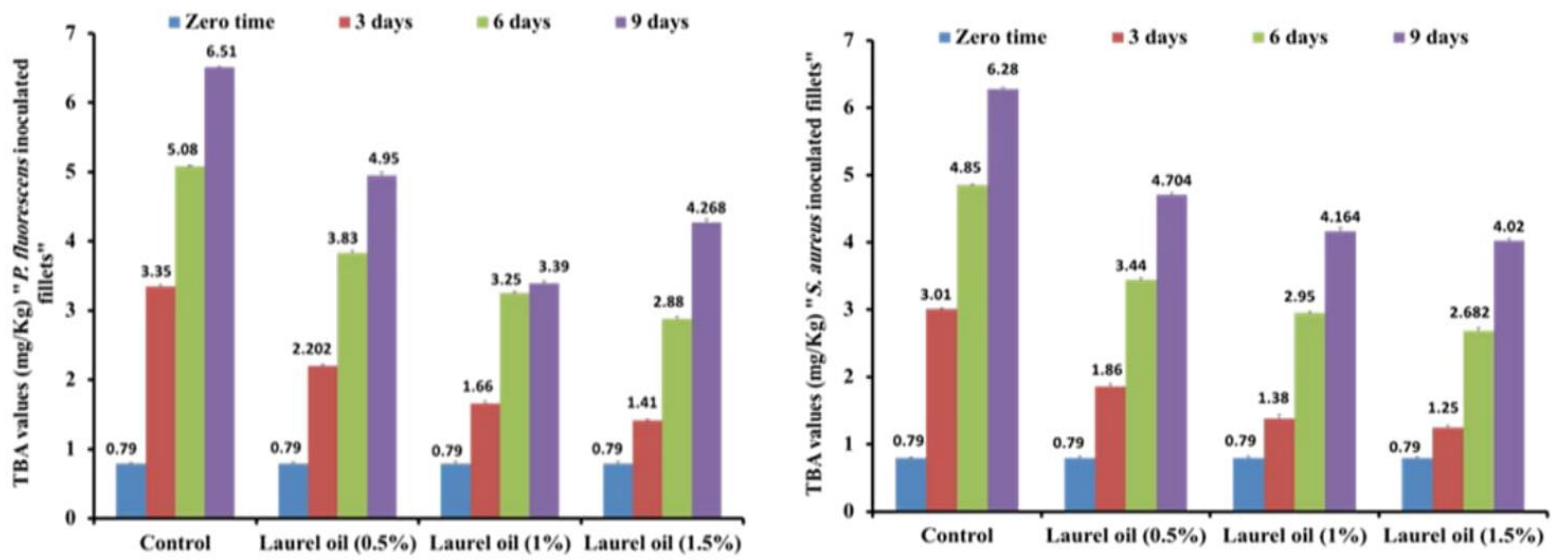

Figure 3: Showing TBA values of S.aureus and P.fluorescence inoculated Oreochromis niloticus fillets for control and Laurel oil $(0.5 \%, 1 \%, 1.5 \%)$ concentration at different storage time 


\section{Chemical evaluation}

The mean $\mathrm{pH}$ values of the examined Oreochromis niloticus fillets inoculated with $S$. aureus and P.fluorescence showed gradually decrease after addition of laurel oil in compared to the untreated group. Differences associated with the examined samples of the $\mathrm{pH}$ values between different concentration of oil and different storage time were highly significant $(\mathrm{P}<$ 0.05) (Fig.1).

Different concentration of laurel oil showed significant decrease in the mean TVB_N (mg $\%$ ) value at different storage time; the most significant record was at $1.5 \%$ laurel oil after the 9 day of treatment by $17.99 \pm 0.01$ for $S$. aureus inoculated fillets and $16.85 \pm 0.01$ for P.fluorescence, compared to untreated fillets. Showed in (Fig. 2). Also, laurel oil showed significant decrease in the mean value of TBA $(\mathrm{mg} / \mathrm{Kg})$ at different storage time, but the highest significant value was at $1.5 \%$ concentration after the 9 day of treatment by $4.02 \pm 0.01$ and $4.27 \pm$ 0.01 for $S$. aureus and $P$. fluorescence respectively compared to un treated fillets that was $6.28 \pm 0.01$ and $6.51 \pm 0.01$ after the 9 day (Fig. 3).

Data is presented as means $\pm \mathrm{SE}$. Mean values followed by different small (lowercase) letters indicates significant effect of the time factor with the same treatment. While, mean values followed by different uppercase letters indicates significant effect of time factor between the different treatments $(\mathrm{P}<0.05)$.

\section{Discussion}

The present study reported that, treatment of Oreochromis niloticus fillets, experimentally infected with $S$. aureus by intensity $3 \times 10^{6} \mathrm{lg}$ with Laurel essential oil with different concentration $(0.5 \%, 1 \%, 1.5 \%)$ at different storage time, it showed various reduction percent as follows; at $0.5 \%$ concentration it showed reduction by $40 \%, 75.26 \%$ and $86.9 \%$ after 3,6 and 9 day of treatment At $1 \%$ concentration the reduction percent was $67.86 \%, 98.22 \%$ and $99.91 \%$ after the 3,6 and 9 day of treatment, While the concentration $1.5 \%$ of Laurel oil showed the higher reduction percent was
$98.63 \%, 99.97 \%$ at 3 and 6 day of treatment and $100 \%$ after the 9 day, as showed in (Table1).

While, fillets infected with P.fluorescence displayed different reduction percent with laurel oil , it was $21.33 \%, 62 \%$ and $69.13 \%$ after the 3, 6 and 9 day of treatment respectively ,at $0.5 \%$ concentration while at $1 \%$ concentration it showed $48.67 \%, 70.12 \%$ and $93.89 \%$ reduction percent after 3, 6 and 9 day of treatment, the higher reduction percent was at $1.5 \%$ concentration of oil by $82.43 \%, 94.15 \%$ and $100 \%$ after 3,6 and 9 day of treatment, as showed in (Table 2).

Another study has been found, that Eucalyptol that is the main component of laurel essential oil inhibit growth of S. aureus at the concentrations of $0.7 \%, 0.6 \%$ and $1 \%$ (16). while other, reported that Pseudomonas spp. were very sensitive to the essential oil of Laurel even very diluted (17). The present study concluded that, $S$. aureus and P. fluorescence are sensitive to different concentration of laurel oil due to the great number of different chemical compounds found in essential oil (18). The major constituents were eucalyptol (27.2\%), alpha terpinenyl acetate $(10.2 \%)$, linalool (8.4\%), methyleugenol (5.4\%), sabinene $(4.0 \%)$ and carvacrol (3.2\%) (5).

Eucalyptol is known to possess a strong antioxidant activity and antibacterial action against Staphylococcus aureus, Linalool is an aliphatic alcohol with strong to moderate antibacterial activity against several bacteria, such as Shigella sonnei, S. flexneri, Pseudomonas spp. and L. monocytogenes (16). S. aureus showed more reduction than $P$. fluorescence, this may be due to sensitivity of different Pseudomonas towards different antibiotics this sometimes paradoxical and it displays an intrinsic resistance to wide variety of essential oils (17).

Measuring of $\mathrm{pH}$ is used as indicator to evaluate the shelf life and quality of the fish fillets. Lipid and protein oxidation consider the main cause of reducing meat quality leading to offflavor and rancidity, increasing value of TVN indicate incidence of spoilage of fish after different periods storage reaching $20 \mathrm{mg} / 100 \mathrm{~g}$ if 
increased the meat decomposing occur, otherwise TBA number was related to the oxidation in meat causing rancidity (19).

The $\mathrm{pH}$ value was measured for control and different treatment of oil at different storage time, the results revealed that; the mean $\mathrm{pH}$ value of untreated groups showed marked change to alkalinity $(7.69,7.97)$ after the 9 day, as showed in (Fig.1). this indicated that the fish fillets was rapidly deteriorated, then after treatment with laurel oil the values of $\mathrm{pH}$ decreased gradually for maintaining the border line $\mathrm{pH}$, also, ANOVA analysis indicated that there is low significance effect of the time factor within the same treatment, while there was a great significant of time factor for different oil treatment in compared with untreated group $(\mathrm{P}<0.05)$. By measuring TVB-N it was found that, different concentration of laurel oil showed significant decrease in the (TVB_N) value at different storage time in compared to control; The most significant record of mean TVN was $1.5 \%$ laurel oil after the 9 day of treatment, followed by $1 \%$ concentration, followed by $0.5 \%$, as showed in (Fig.2). ANOVA indicated that there was high significance $(++)$ between different storage time of the same treatment group, and also, high significance of time factor between different treatment "control, $0.5 \%, 1 \%, 1.5 \%$ ".

TBA number was measured for control and oil treated fillets and the results showed in (Fig.3), revealed that; different concentration of Laurel oil showed significant decrease in TBA value at different storage time in compared to control ; The most significant record of TBA was $1.5 \%$ Laurel oil after the 9 day of treatment, followed by $1 \%$ concentration, followed by $0.5 \%$. The ANOVA indicated that there was a high significance $(++)$ between the time factor within both the same treatment and between different treatment.

Laurel essential oil with different concentration $(0.5 \%, 1 \%, 1.5 \%)$ maintain value of TBA that indicate decreasing of oxidative rancidity causing spoilage, thus Laurel oil suggested to has anti-oxidant properties. another matching study, reported that essential oil from laurel, eugenol and methyl eugenol may be considered the main mediators of antioxidant activity (20).
The antioxidant activity of eugenol has been reported in several studies and there are few reports regarding the radical scavenging activity of the constituents of bay laurel leaves. It was concluded from the present study that Laurel essential oil has strong antibacterial activity against Staphylococcus aureus and Pseudomonas fluorescence and it can inhibit growth of these bacteria with its different concentrations; also, treatment of Oreochromis niloticus fillets with laurel oil, help in keeping quality of fish fillets and prolong fillets shelf life, in addition to the anti-oxidant activity of laurel oil that maintain fillets freshness and prevent lipid peroxidation, so that enhance shelf life for a period of time

\section{Conflict of interest statement}

None of the authors have any conflict of interest to declare.

\section{Acknowledgment}

This research has been done with the support of Food and Feed Safety Laboratory, Faculty of Veterinary Medicine, Damanhour University and Faculty of Aquatic and Fisheries Science, Kafrelsheikh University.

\section{References}

1. Ghaly AE, Dave D, Budge S, Brooks M. Fish spoilage mechanisms and preservation techniques. American Journal of Applied Sciences. 2010; 7: 859

2. Vaclavik VA, Christian EW. Food Preservation. Essentials of food science: Springer; 2014. p. 323-42.

3. Seely KA, Lapoint J, Moran JH, Fattore L. Spice drugs are more than harmless herbal blends: a review of the pharmacology and toxicology of synthetic cannabinoids. Progress in Neuro-psychopharmacology and biological psychiatry. 2012; 39: 23443.

4. Tajkarimi M, Ibrahim SA, Cliver D. Antimicrobial herb and spice compounds in food. Food control. 2010; 21: 1199-218.

5. Ramos C, Teixeira B, Batista I, Matos O, Serrano $\mathrm{C}$, Neng $\mathrm{N}$, et al. Antioxidant and antibacterial activity of essential oil and extracts of bay laurel Laurus nobilis Linnaeus (Lauraceae) from Portugal. Natural product research. 2012; 26: 518-29.

6. Stoskopf MK. Fish medicine1993. 
7. Tassou C, Drosinos E, Nychas G. Effects of essential oil from mint (Mentha piperita) on Salmonella enteritidis and Listeria monocytogenes in model food systems at 4 and $10 \mathrm{C}$. Journal of Applied Bacteriology. 1995; 78: 593-600.

8. Tandon S, Rane S. Decoction and hot continuous extraction techniques. Extraction technologies for medicinal and aromatic plants. 2008; 93.

9. González R, Tamagnini L, Olmos P, De Sousa G. Evaluation of a chromogenic medium for total coliforms and Escherichia coli determination in ready-to-eat foods. Food microbiology. 2003; 20: 601-4.

10. Aycicek H, Cakiroglu S, Stevenson TH. Incidence of Staphylococcus aureus in ready-to-eat meals from military cafeterias in Ankara, Turkey. Food control. 2005; 16: 531-4.

11. Hassan M, Shaltout F, Maarouf A, El-Shafey W. Psychrotrophic bacteria in frozen fish with special reference to Pseudomonas species. Benha Veterinary Medical Journal. 2014; 27: 78-83.

12. Chan ST, Yao MW, Wong Y, Wong T, Mok C, Sin DW. Evaluation of chemical indicators for monitoring freshness of food and determination of volatile amines in fish by headspace solid-phase microextraction and gas chromatography-mass spectrometry. European Food Research and Technology. 2006; 224: 67.

13. Howgate P. A critical review of total volatile bases and trimethylamine as indices of freshness of fish. Part 1. Determination. Electronic Journal of Environmental, Agricultural \& Food Chemistry. 2010; 9 .
14. Pikul J, Leszczynski DE, Kummerow FA. Evaluation of three modified TBA methods for measuring lipid oxidation in chicken meat. Journal of Agricultural and Food Chemistry. 1989; 37: 1309-13.

15. Nabil M, Edris A, Shaltout F, Zakaria I. Effect of some preservatives on bacterial load of some poultry meat products. Benha Vet Med J. 2014; 26: 94-103.

16. Zengin H, Baysal AH. Antibacterial and antioxidant activity of essential oil terpenes against pathogenic and spoilage-forming bacteria and cell structure-activity relationships evaluated by SEM microscopy. Molecules. 2014; 19: 17773-98.

17. Bennadja S, Kaki YTA, Djahoudi A, Hadef Y, Chefrour A. Antibiotic activity of the essential oil of laurel (Laurus nobilis L.) on eight bacterial strains. Journal of Life Sciences. 2013; 7: 814.

18. Lahlou M. Methods to study the phytochemistry and bioactivity of essential oils. Phytotherapy Research: An International Journal Devoted to Pharmacological and Toxicological Evaluation of Natural Product Derivatives. 2004; 18: 435-48.

19. El-Deen G, El-Shamery M. Studies on contamination and quality of fresh fish meats during storage. Academic journal of biological science. 2010; 2: 65-74.

20. Politeo O, Jukić M, Miloš M. Chemical composition and antioxidant activity of free volatile aglycones from laurel (Laurus nobilis L.) compared to its essential oil. Croatica chemica acta. 2007; 80: $121-6$. 